\title{
El taller de cerámica como vehículo de intercambio en un territorio complejo.
}

The ceramic workshop as an exchange vehicle in a complex territory.

\section{Consuelo Crespo}

ISSN (imp): 1390-4825

ISSN (e): 2477-9199
Fecha de recepción: 03/2017

Fecha de aceptación: 06/2017

\begin{abstract}
Resumen:
Memorias Tangibles de Tulipe (METATU) es una investigación, que usa los mecanismos de las prácticas participativas del arte, como vehículo de intercambio en un complejo campo de interacción al noroccidente de Pichincha, en un territorio demarcado por las huellas materiales dejadas por los Yumbos -pobladores antiguos- y por los afloramientos de arcilla en el borde de sus caminos y quebradas. El interés por el capital simbólico y por la construcción del "sentido", en el territorio, se genera entre pugnas de los diferentes actores sociales: el Estado Desarrollista, el Estado Patrimonialista, la Iglesia y los actuales pobladores con sus diversos significantes. En esta investigación se prioriza la mirada del colono en relación con el espacio en su día a día, en la construcción de sus subjetividades y en su relación con el entorno. La investigación pretende mostrar el "campo" de la cultura específico de noroccidente, su multiplicidad y su antagonismo, atravesado por la "mirada" de las diferentes instancias de poder que franquean las visualidades en un "paisaje" que arrastra siglos de interacción entre lo humano y una naturaleza vulnerable.
\end{abstract}

Palabras clave: Cerámica. Colonos. Comunidades. Investigación-creación artística. Noroccidente de Pichincha. Talleres

\begin{abstract}
:
"Memorias Tangibles de Tulipe" (METATU) is a research project that aims to understand a complex "field" of interaction in the North West of Pichincha, uses participative art practices and the clay outcrop on the board road, and is set by an ancient population called Yumbos. Here the search for symbolic capital is divided and each actor struggles for contributing to constructing "perception". Progressive and Patrimonial State, Religion and settlers are elements in this struggle. Settlers' sight is highlighted over other points of view because their prejudices are built over relations, that are not always understood, and which are the ones that relates daily to the territory. This research creates a visual culture "field", crossed by the "sight" of different power stages of power. This clears the image of a "landscape" that carries centuries of human interaction with the vulnerable nature.
\end{abstract}

Key words: Ceramics. Colonists. Communities. Art - Research - Creation. NorthWestern Pichincha. Workshops.

\author{
Autora: \\ Consuelo Crespo (1961), ecuatoriana. Licenciada en Artes Plásticas, Escultura (Universidad \\ Central del Ecuador), Magíster en Estudios de la Cultura, Artes y Estudios Visuales \\ (Universidad Andina Simón Bolívar), Docente-investigadora (Pontificia Universidad Católica del \\ Ecuador). Exposición individual "El lugar de la sospecha" Galería Procesos Ecuador, exposición \\ colectiva "Ya no es mágico el mundo" Centro de Arte Contemporáneo, Ecuador.
}




\section{La investigación en el campo de las artes.}

\section{El arte como un objeto del conocimiento y como un mecanismo de desentrañamiento de la realidad.}

Memorias Tangibles de Tulipe (METATU), es una investigación de la Carrera de Artes Visuales de la Pontificia Universidad Católica del Ecuador que se realizó entre 2014 y 2016 con los colonos de las poblaciones de Tulipe, Pacto y Anope, en el cantón Pedro Moncayo, provincia de Pichincha. Esta investigación se inscribe en una práctica docente que usa los mecanismos de las prácticas participativas del arte para buscar otros públicos, indagar otras estéticas y otras perspectivas que generen cuestionamientos en la interpretación de la consciencia y del espacio circundante (Fajardo, 2008). Las prácticas participativas se recuperaron en la modernidad ${ }^{1}$, cuando occidente "expande el campo" de comprensión y acción de las prácticas artísticas $y$, entre otros debates, da importancia a las relaciones de intercambio entre los diferentes actores $^{2}$ que participan durante el proceso de producción, de creación y de exhibición de los eventos artísticos (Krauss, 1979). En América Latina estas prácticas migraron a intervenciones que redefinen el campo de lo social y de lo político, no solo de lo cultural (Cámara, 2015). En el caso de METATU, las prácticas están insertas en el campo de la investigación académica de las artes, cuyo intercambio no ocurre como una provocación sino dentro del uso de las normas éticas aplicadas en las ciencias sociales y en la etnografía. (Guber, 2001) (Jäger; 2003)

El campo de acción e interrelación de las artes está abriendo siempre nuevos significantes para aproximarse a lo real y a la realidad construida, para mediar entre el signo y el sentido. Esta contingencia está atravesada por el lenguaje del universo cultural inmerso

1 Entre las diferentes migraciones del arte en la modernidad estuvo la que hizo énfasis en las relaciones $\mathrm{y}$ en las provocaciones, tomando en cuenta cómo en cada realidad esta práctica toma diferentes posturas con respecto a su entorno.

2 Buscando "comprender los fenómenos sociales desde la perspectiva de sus miembros (entendidos como "actores", "agentes" o "sujetos sociales")". (GUBER, 2001) en un espacio-tiempo específico que incluye al sujeto en su existencia. Esta existencia entendida como un cumulo de experiencias sensibles en la creación de los objetos que organizan el espacio-medio donde ocurre la trama social y donde se ratifica la veracidad del mundo creado, "la realidad" (Gadamer, 1993), para que la vida suceda a partir de hábitos, costumbres, performatividades y ritualidades donde opera el intercambio (Latour, 1998). Los encuentros se producen a través de diferentes experiencias, procesos de producción y de exhibición generados en el taller y, a partir de ellos, suscitar en los actores y sus públicos posicionamientos con respecto al entorno geológico, al entorno social y cultural (Cámara, 2015).

La investigación usó el método de análisis historiográfico para establecer el lugar desde donde se formulan las enunciaciones socio culturales que se han instituido desde los diferentes dispositivos del saber académico.

El Análisis del Discurso lo usamos como una metodología que da cuenta de cómo el "conocimiento" es una práctica discursiva que se "manifiesta" o se "materializa" en los eventos, en los actos y en los objetos con sus usos. Estos se organizan como redes o dispositivos que pueblan el universo societal. El análisis del discurso problematiza el lugar desde donde se inscriben estas prácticas y nos permite identificar las "resistencias" de los sujetos a integrarse a este espacio complejo. Identifica estas situaciones para derivar nuevas relaciones con los objetos y con la producción de los mismos para generar nuevas miradas (Meyer, 2003), (Jäger, 2003).

En el campo científico, hemos recorrido el territorio para identificar los lugares donde podríamos encontrar el material cerámico, estas salidas nos ayudaron a escoger los lugares donde coincidían algunas circunstancias sociales, culturales, geográficas y geológicas.

Con estos parámetros la pregunta sería: ¿Cómo provocamos en los pobladores de las localidades del noroccidente un acto de resistencia dentro de un sistema naturalizado por la cultura, la ideología y el discurso? ${ }^{3}$ (Jäger,

3 Siegfried Jäger se aproxima a la idea de "discurso" a partir de las nociones estructuralistas Michel Foucault y hace énfasis en la relación que tiene el sujeto con el objeto. 
2003). Para plantear esta problemática, realizaré un corte diacrónico e investigativo, sobre las diferentes reflexiones académicas que designan el campo epistemológico de la región, y un corte sincrónico y empírico para establecer la relación entre los diferentes actores y apreciar la actual pugna de poder por la representación del espacio específico.

\section{Un corte diacrónico}

\section{Los afloramientos de arcilla que habilitan los talleres.}

El interés del equipo de investigación académica desde un conocimiento científico y empírico se encaminó por una serie de coincidencias:

a. Noroccidente de Pichincha es una zona cuya característica geofísica -una cordillera jovennos hizo pensar que allí habrían yacimientos de arcilla. Se exploró y encontró, afloramientos de arcillas y de materiales cerámicos, en el sector de Nanegalito, Tulipe, Gualea, Ingapí, Pacto, Buenos Aires y Anope, llegando hasta las riveras del río Guayllabamba, en el límite provincial con Imbabura.

b. Los hallazgos arqueológicos de noroccidente de Pichincha y sus publicaciones, sobre los habitantes antiguos, han consolidado la construcción de la imagen del Estado Nación.

c. Noroccidente de Pichincha a pesar de ser una zona cercana a Quito ha sido poco intervenida por el Estado, sino hasta mediados del siglo pasado, por lo que el campo está abierto para la investigación.

Estas tres condiciones nos llevaron a proponer los talleres de cerámica como un proyecto de investigación -Memorias Tangibles de Tulipe (METATU)- dentro del campo de las artes. La investigación-creación-artística se realizó en las poblaciones de: Tulipe -alineada con la línea ecuatorial hacia el Norte $00^{\circ} 05^{\prime} 52^{\prime \prime}$ , ubicada en el valle de Tulipe coincidiendo entre el límite de las parroquias de Nanegalito y Gualea. Y las poblaciones de Pacto y Anope en la parroquia de Pacto. Estas poblaciones son parte del cantón Pedro Moncayo, hoya del río Guayllabamba, ubicadas entre 40 y 60 kilometros al norte de la ciudad capital, y cuyas coordenadas son parte del Distrito Metropolitano de Quito. La característica geomorfológica de la región está tejida entre las estribaciones occidentales del volcán Pichincha, en la cordillera del Chocó que forma parte de la cordillera de los Andes, de donde brotan las vertientes que alimentan el río Guayllabamba y que junto a la briza de la costa del océano Pacífico dan origen al bosque húmedo montano característico del sector.

La investigación siempre tuvo el interés de habilitar el uso de las arcillas cerámicas, de manera sustentable sin causar dańos en el entorno, como materia prima indispensable en la construcción de objetos de alfarería, permitiendo nuevas formas de intercambio entre nosotros y las comunidades.

\section{Un pasado material silencioso que da fe de una existencia desaparecida}

Noroccidente de Pichincha, antes de la conquista y la colonización española, estuvo habitado por los "Yumbos", a quienes Franz Salomon en su libro: Los Señores Étnicos de Quito en la Época de los Incas (1980), los describe como los antiguos pobladores de noroccidente, situados en el territorio de forma autónoma y atomizada, estableciendo entre ellos vínculos religiosos y políticos, con fronteras móviles, que vinculaban su lenguaje, sus saberes, sus costumbres y sus creencias inmersas en el mundo de lo cultural. Esta ocupación espacial y cultural se organizó en forma de "mecanismos no-centralizados, (...) contrario de aquello que se da en los estados y en los imperios" (Salomon, 1980). Salomon (1980) realizó una investigación arqueológica, etnográfica y de estudios de la arquitectura, desde una posición "positivista" en base a la observación empírica de las huellas, sin la emergencia de ser presentadas como una realidad última. Salomon usa una categoría etnográfica para nombrar los pueblos antiguos, como "Señores Étnicos", con una cierta distancia.

Los Yumbos modelaron el paisaje, manipularon la vegetación y organizaron el espacio de convivencia con emplazamientos visibles, como: las terrazas, las tolas (pirámides truncas), los pucaras, las piscinas, los senderos y los objetos cerámicos y líticos que nos dan cuenta de su organización social, de su religiosidad y de su conocimiento geológico y astronómico, nos transfieren significados aún en la actualidad, 
disponiendo el territorio con una presencia silenciosa que interpela el presente. (Rhoades, 2001)

Durante la colonia, desde el siglo XVI hasta el siglo XVIII, los yumbos mantuvieron una cierta autonomía en su accionar dentro del territorio, no se implementaron accesos ecuestres lo que les permitió continuar con su acostumbrado tráfico de mercancías desde la costa hasta la sierra y viceversa (Valarezo, 2001). Debido a las presiones que ejerció la colonia durante los siglos XVIII y XIX, la desaparición de los yumbos se concretó, ya sea por migraciones causadas por la erupción del volcán Pichincha o por su auto inmolación como práctica de resistencia. Galo Valarezo, en: "La tierra y la sociedad de Nanegal desde los tiempos aborígenes", en (Rhoades, 2001), dice:

La resistencia dirigida por el poder escondido y subterráneo de los shamanes no se desató en una guerra contra el poder colonial; fue ejecutada como un acto de auto-destrucción, el último recurso de los oprimidos y derrotados. (...) Los factores que llevaron a la guerra shamánica, estuvieron directamente relacionados con la presión colonial de abrir vías y (por) el control que los Mercedarios ejercían sobre el intercambio, (...) coincidiendo con la consolidación de las vastas haciendas". (Valarezo, 2001, pp. 41)

Si bien este hecho no es verificable, nos habla de una resistencia de los pobladores a someterse e integrarse a las diferentes prácticas colonizadoras.

\section{La iglesia como captadora de prácticas por lo tanto de voluntades y señalizadora de espacios}

La iglesia ejerció como mediadora de territorios y poblaciones, pues en la colonia se entregó a los Mercedarios grandes territorios para evangelizar y catequizar a los pobladores, causando desavenencias.

La enemistad entre los yumbos y los Mercedarios fue demostrada en el incendio de la iglesia de Guagpi (...). (...) Los españoles no pudieron convertir a los yumbos, quienes resistían hasta el final. (...) Desde el punto de vista de los españoles, los yumbos (...) eran irrazonables y "monstros" por su resistencia a la conversión religiosa. (Valarezo, 2001, pp. 41)

En el siglo XX los colonos mestizos tuvieron un vínculo estrecho con la iglesia, la cual aprovechó su autoridad, usando el espacio dominante de los emplazamientos construidos por los yumbos, aprovechando su visibilidad y su capacidad de simbolizar, se apropió de las iconografías pasadas para modelar las nuevas. (Scollon, 2003)

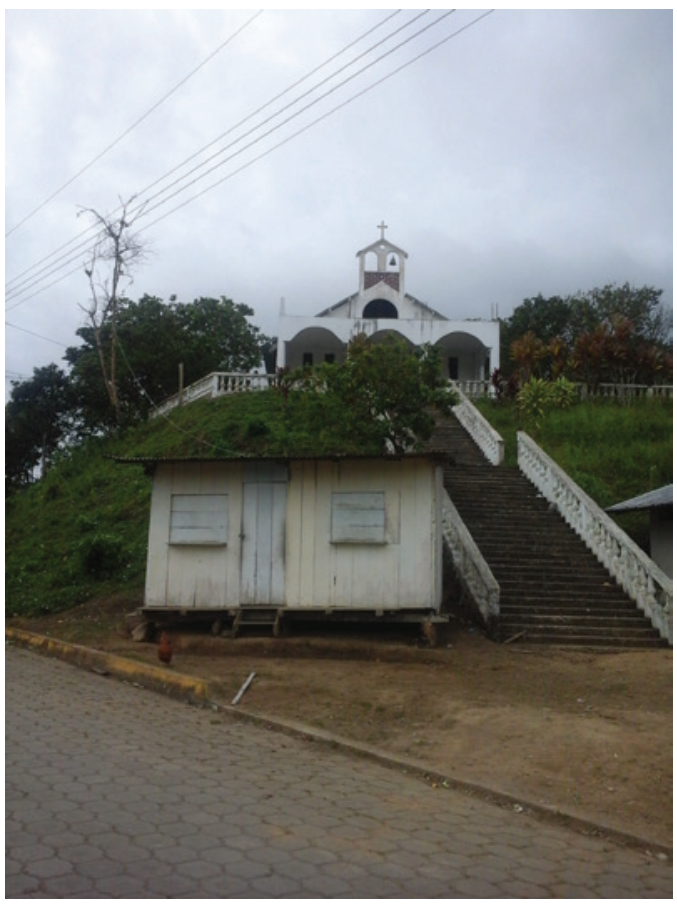

Figura 1. Tola e iglesia en Sanhuangal

\section{El Estado moderno desarrollista}

En la década de los cuarenta del siglo XX el Estado-Nación moderno desarrollista construyó las carreteras: Quito-Nono-Tandayapa, Pedro Vicente Maldonado-Puerto Quito, NanegalSelva Alegre y Nanegal-Gualea-Pacto, abriendo el camino a colonos de diferentes zonas del país, hecho que cambió el paisaje de noroccidente, propiciando la tala del bosque primario y secundario. (Valarezo, 2001)

La señora Lili Miño (52 años), hija de un colono que entró en la zona en los años cincuenta y que en el 2014 estuvo de administradora del museo, comenta como llegó su padre a Tulipe:

Mi padre era maderero, llegó abriendo 
trocha allá por los cincuenta, yo ya nací aquí. Cuando íbamos a Quito para comprar alimentos... íbamos a lomo de mula por los culuncos... la palabra culunco es una metonimia del sonido que hacen las patas de las mulas al caminar en el lodo. (Miño, 2014)

Su relato tiene una visión ya asimilada del paisaje e incluso nos ratifica que ha accedido al discurso del mito de la Nación y que es parte de su consolidación.

En la década de los setenta las haciendas, de las parroquias de Nanegal, Nanegalito, Gualea y Pacto, vendieron a sus antiguos jornaleros pequeñas parcelas y, en 1979 el IERAC (Instituto Ecuatoriano de Reforma Agraria y Colonización) asignó a los colonos sin tierra los territorios baldíos pertenecientes al Estado (Valarezo, 2001).

Para visualizar este conflicto he escogido una entrevista con don Israel Guillen (68 años), colono llegado en la década de los setenta y propietario de una tienda de víveres en Sanhuangal, población entre Anope y el río Guayllabamba:

Acordarse, es una historia larga, los terrenos allá en Loja eran secos no había agua, trabajábamos para los dueños de hacienda como peones, trabajábamos una semana para uno, otra semana para la hacienda, nos daban unos lotecitos para que ahí sembremos nosotros, cuando tocaba hacer para uno, tocaba hacer por ahí mandos, coger yeguas, coger burros, coger ganados, cualquier cosa, uno trabajaba tres días, par diítas para uno, y vuelta tocaba ir a la hacienda a limpiar las cañas que había en ese tiempo.

Allá era seco, aquí es bonito, el aire mismo es fresquito y allá había sol y viento... Caminábamos para entrar a las tierras por un camino que había de aquí a Anope, de Anope salíamos recto del río Anope al Paraíso, ya llegábamos al Paraíso y no salíamos a la carretera sino que nos bajábamos recto, salíamos cerca de Pacto; en ese tiempo había chaquiñanes, antes se llamaba el "Camino Real", andaba todo el mundo, así le decíamos nosotros, andaba todo el que caía por aquí, cuatro horas se hacía a pie a Santa Rosa, ahora media hora en carro, hacíamos de cuatro horas a cinco horas a pie, cayendo, levantando. Lodo, todo era lodo en tiempo de invierno, para pasar esas quebradas teníamos que cruzar un palo" (Guillen, 2015).

Esta narración nos permite visualizar el nivel de asimilación de los colonos con su entorno y como el migrante que abre trocha tiene que llevar a cuestas su propia historia. El Estado-Nación buscó incorporar estas tierras a la producción.

Cuando íbamos a confirmar la realización de los talleres en Pacto, nos encontramos con que, se estaban desarrollando votaciones para decidir si permitían o no la exploración y explotación de los recursos geológicos a pesar de ser zona protegida. La Sra. Yolanda Velazco, con quien contactamos para la realización de los talleres, estaba sumida en la organización de la consulta, vinculada a agentes del proteccionismo ambiental como son los Yasunidos ${ }^{4}$. La prensa se escribió sobre el tema:

El 12 de abril de 2015, día en el que las comunidades de Pacto realizamos la "Consulta Comunitaria de Buena Fe" sobre la extracción minera en nuestra parroquia, es un día histórico para la democracia, para Pacto y para el país. El $92.36 \%$ de votantes decidimos que Pacto sea una parroquia libre de minería. (Yasunidos - Prensa, 2015)

Actualmente el Estado desarrollista pretende legalizar dispositivos de modernización para explotar los recursos geológicos y naturales, este planteamiento genera resistencias y adherencias, por lo tanto conflictos.

4 Es un grupo constituido desde la sociedad civil, ecologista y anti extractivista. 


\section{Los instrumentos o dispositivos modernos de legitimación del Estado Nación}

Por otro lado, la invención del Estado-Nación moderna patrimonializa los objetos, los eventos y las historias, construyendo una "metarealidad" para consolidar su imagen (KirshenblattGimblett, 2004). Fernanda Cartagena y Cristian León en: El museo desbordado: Debates contemporáneos en torno a la musealidad, anotan que: "a través de lo auténtico, artístico o antiguo, asumido como universal, se diseminan valores dominantes. (...) y la actualización de este discurso de poder" (Cartagena \& León, 2014, pp. 78).

Las autoridades gubernamentales manejan la cultura por medio de la patrimonialización y museificación de los emplazamientos y de los objetos memoriales de la zona. El centro ceremonial de Tulipe, los petroglifos de Chirape y los objetos cerámicos son algunas de las huellas tangibles de una cultura que han sido susceptibles a ser patrimonializadas y museificadas, confiriéndoles cualidades culturales universales para consolidar el metarelato de una identidad (Cartagena, 2014), por medio de dispositivos mediadores del discurso como son los museos ${ }^{5}$ (Jäger, 2003).

El "Museo de Sitio de Tulipe", es un dispositivo para inducir "conocimientos" a sus visitantes. Estos conocimientos son la interpretación oficial sobre la cultura Yumbo, sin mostrar la diversidad de criterios que se han escrito, desde los diferentes puntos de vista de los estudios historiográficos, etnohistóricos, arqueológicos. Se seleccionó un solo punto de vista para construir una memoria, consolidar un pasado y constituir un presente nacional donde se disuelven las identidades.

El arqueólogo Hólguer Jara (2006), autor del guion museográfico del Museo de Sitio de Tulipe y del libro: Tulipe y la cultura Yumbo, acoge la categoría de "nación", como una imagen de poder que está constituida dentro del espectro de nuestro acervo cultural implementado por el discurso dominante (Jäger, 2003). Jara asume que había una unidad consciente entre los

5 Son espacios materiales construidos para producir la alegoría que recrea la imagen consolidada de la identidad nacional. (JÄGER, 2003). diferentes grupos que habitaban el territorio, idealizó la contingencia de los eventos que mediaron la existencia de los pobladores antiguos, para convertirlos en patrimonio de la Nación. Jara, dice: "Se entenderá nación como la comunidad de individuos asentada en un territorio determinado con etnia, lengua, historia, tradiciones comunes y consciente de constituir un cuerpo ético-político diferenciado." (Jara, 2006, pp. 111).

Como vimos anteriormente hay otras posiciones que narran el territorio, nombrándolos como "señores étnicos", confiriéndoles a estos grupos humanos diversidad y similitudes (Salomon, 1997). Estas confrontaciones nos permiten observar como la construcción simbólica, por medio de la literatura académica, genera una disputa por el espacio simbólico entre los diversos puntos de vista e intereses sobre la región (Crespo, C., 2017).

La cerámica de noroccidente fue diseñada con fines utilitarios y ceremoniales, fue construida con la técnica de presión, sin ser demasiado ornamentada. Actualmente ocupa un lugar en el museo donde se cristalizan sus sentidos. El museo, en su concepción moderna, aísla los objetos de su entorno, de su transitorio hábito de uso y de su perecedero tiempo útil y establece una lejanía con el día a día de los pobladores actuales. En el caso de que no fuera así, el objeto tendría una relación directa con la performatividad de los colonos, surgiendo en esa relación una paráfrasis directa sin pasar por la interpretación oficial del Estado-Nación. Como, anotó Pierre Nora en: Entre la memoria y la historia: Problemática de los lugares: "El lugar (y objeto) de memoria (tiene) un lugar doble; un lugar encerrado en si mismo, cerrado en su identidad (...), pero constantemente abierto a sus posibles significaciones." (Nora, 2008, pp. 22-23).

El Estado-Nación ha protegido la parte norte del cantón Pedro Moncayo por lindar con la reserva ecológica Cotacachi-Cayapas, patrimonio natural del Ecuador, esto hace de este territorio un sitio idóneo para impulsar el turismo ecológico privado (Mashpi y Maquipucuna), convirtiéndose en otro dirimente en la pugna por la representatividad simbólica de esta geografía, ya que los limites 
de lo privado están demarcados físicamente y cierran sus fronteras, que de alguna manera eran transitables entre los colonos. En estos dispositivos privados que utilizan las simbologías ligadas con lo "natural" no existen políticas para integrar a las comunidades.

\section{La recolonización del noroccidente de Pichincha.}

Los pobladores del territorio inmersos en la cultura de producción extractivista moderna de explotación y consumo comenzaron, a mediados del siglo XX, la tala indiscriminada del bosque y la construcción de accesos carrosables, dando paso al mono cultivo y como resultado a la modificación del ecosistema y por lo tanto del clima.

En Tulipe, podemos observar como la colonización se ha realizado en períodos diferentes y eso marca una desigualdad en su estructura social. Si bien los primeros colonos, ingresaron de forma precaria y con el tiempo accedieron a las tierras, sus hijos ya recibieron educación y sus nietos, en su mayoría, estudia en la capital. Pero el flujo de colonos es constante y ahora podemos observar como los nuevos colonos están empleados en los negocios y propiedades de los primeros.

La diversidad de orígenes de los colonos, que pueblan noroccidente, hacen de su geografía un mosaico de conocimientos e influencias que no llegan a materializarse como una unidad. Las personas vienen de Loja, de Cuenca, de Ambato, de Santo Domingo, de Esmeraldas, de Colombia, etcétera. Son pobladores que llegaron como jornaleros, madereros, procesadores de aguardiente, etcétera en busca de oportunidades y de trabajo. La nueva tierra materializa sus expectativas a pesar de no dejar sus memorias.

Don Israel Guillen nos siguió narrando:

Vinimos buscando terreno para trabajar, allá, Loja era viejo, seco, no había nada de nada. Aquí hay mitad cuencanos mitad lojanos, mitad, mitad. Todos familias, pocos son extraños, familias más que todo, mis hermanos, sobrinos, ahorita ya hay nietos también. Uno se ponía a trabajar porque no había más que hacer, sembrábamos platanitos para comer... como no había... donde sacar el producto, había que consumir. En la tierra mismo sembrábamos, lo que avanzábamos comíamos lo demás se quedaba ahí en la tierra, se podría pues, porque no había donde vender, todos tenían cada cual su pedacito para sembrar su pite fréjol, el maíz... Vinieron familias del Azuay, familias de mi señora vinieron, decían: "vamos más allá de Pacto, hay terrenos para adentro, son terrenos baldíos, en lugar de estar trabajando para dueños de hacienda. No quería venir yo, me daba no se que, porque en primer lugar no había plata, tenía mis hijos mi señora que les iba a dejar botando, de ahí mi señora me dice ándate dicen que está bonito. Octubre creo vine y llegué noviembre, diciembre, lindos soles hacia bonito, una prima de mi señora me dijo le vendo ese pedacito y cogí. (Guillen, 2015)

Don Álvaro Flor (67 años), colombiano colono de Anope, ceramista conocedor de la elaboración de hornos, se resiste a incorporarse a este nuevo paisaje:

Yo vengo de Colombia, el martes completo ochenta y cuatro, el martes 5 de mayo. Soy del Cauca, del valle del Cauca, cincuenta años estoy aquí, porque a mí me trajeron en el año 1962 y de ahí hasta el 2015, me trajeron yo no se por qué... Tenía mi mujer, mis hijos pequeñitos, aquí estudiaron, unos son nacidos en Colombia otros son nacidos aquí, tres veces nos fuimos $y$ tres veces me fueron a traer, no me enseñaba oiga, no me gustaba aquí... junto, junto con mi mujer. La primera vez me mando a ver un hermano Julio, la segunda vez mando otro hermano Alonzo Flor, hasta que nos enseñamos. (FLOR, 2015) 
Los colonos vienen cargados de vidas y recuerdos, de lugares y de historias, y su adaptación al espacio depende del modo en que el lugar le signifique. (Lacan, 1964)

\section{Un corte sincrónico y empirico}

\section{En diálogo con las circunstancias}

En las caminatas en busca del material hicimos contacto con los las personas que querían participar en el taller. Estas personas acudieron a sus memorias para ubicar los yacimientos, rememorando sus pasos y recorridos de la infancia, la adolescencia y la vida de adulto. Esta memoria se establece a partir de su relación con el territorio transitado y por lo tanto sentido, diferenciando e identificando las arcillas, por las cualidades físicas que contrastan con la greda común. Ellos conocen dónde están los afloramientos por su larga convivencia con la geografía y por la capacidad lúdica de contactar con el espacio.

La arcilla es una roca sedimentaria formada por un proceso de descomposición, por presión del agua y por el calor de las capas geológicas. Las arcillas "primarias" son las que afloran en el lugar donde se formaron, como las que encontramos en la cresta de montaña y se deja ver al borde del camino y en las riveras de los ríos: Anope, Ingapi y Tulipe, Las arcillas sedimentarias son las que han sido arrastradas por deslizamientos y yacen en los valles como las de Pacto y las de las cuencas del río Guayllabamba.

En Anope, la arcilla fue el vínculo entre la comunidad y los investigadores porque encontramos el afloramiento a pocos pasos de la plaza central, muy cerca de su vida diaria y de los juegos de los niños, entre la vía, Anope y Sanhuangal. Don Alipio Mora (68 años) venido de Esmeraldas, propietario de una pequeña finca, se apersonó de la excursión que nos iba a mostrar la arcilla y nos pidió a cambio los talleres.

Esta arcilla es blanca, abajo hay una mina más grande. (...) ¿les damos la arcilla pero qué dan a cambio? (Mora, 2015), Anope

En Pacto, cuyas participantes fueron todas mujeres, en el primer contacto algunas de ellas nos anunciaron que conocían algunos afloramientos por lo que acordamos que cada una traiga el barro de donde lo habían visto. La arcilla está muy presente en la comunidad de Pacto, posiblemente porque corresponderían a depósitos sedimentarios y no afloraciones primarias.

En Tulipe, los talleristas son migrantes recientes que no han crecido en la zona y no recuerdan los lugares donde encontrar arcilla, por lo que los investigadores tuvimos que recorrer el entorno, explorando en busca del material y lo encontramos al borde de la carretera un kilómetro antes de llegar al pueblo. Los talleristas nos comparten los saberes cotidianos:

Abajo al lado del río, donde se murió una baca, hay una arcilla bien blanca y pegajosa... (Cordova, M. 2014), Tulipe. (Arcilla a la cual no pudimos acceder ya que el dueño de la propiedad no estuvo de acuerdo).

Por Sanhuangal, en la parte más caliente, ahí disque hay ese lodo que se pega. Cuando se va por Chontal también. (Merino, 2015) Tulipe.

\section{Los talleres}

El taller es una práctica que agrupa a una serie de personas alrededor de intereses en común. Los intereses en común que compartimos entre investigadores y colonos fue el intercambio de conocimiento. Por parte de los investigadores se compartiría el conocimiento de las tecnologías cerámicas -su extracción, procesamiento y producción- para inscribirlas en sus saberes y por el lado de los colonos nos transmitirían las reflexiones sobre su procedencia para la constitución de una subjetividad, sobre las nociones que ellos socializarían en torno a sus luchas cotidianas y a cómo se relacionan con el entorno social, cultural y político, para poder generar en conjunto un discurso crítico sobre su realidad. (SCOLLON, 2003)

Después de una introducción en el espacio de la comunidad con caminatas de reconocimiento y una narración del espacio físico y simbólico del lugar, se acordó un cronograma 
para la realización de los talleres, se estableció las actividades y las responsabilidades y se explicó la metodología.

Fue importante que los talleristas se comprometan en el proceso de recolección y procesamiento de la pasta, así se responsabilizarían de la extracción sustentable del recurso geológico.

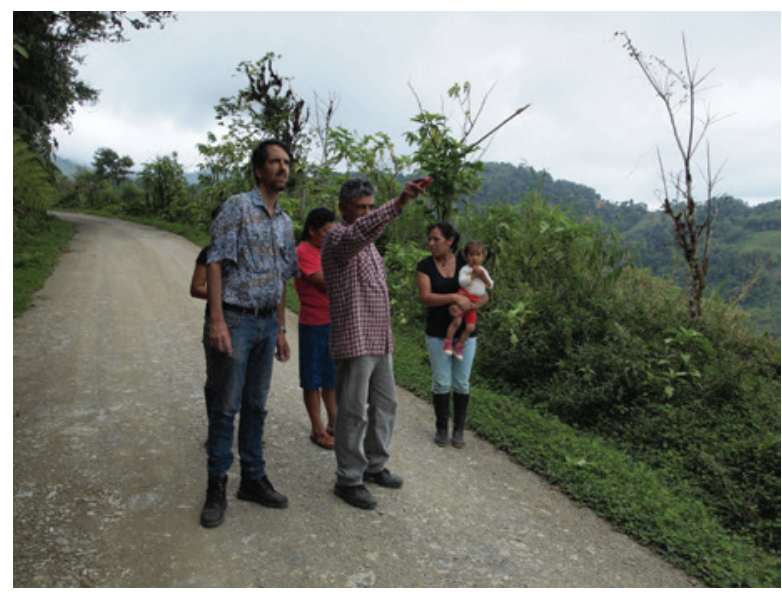

Figura 2. Caminata en Anope.

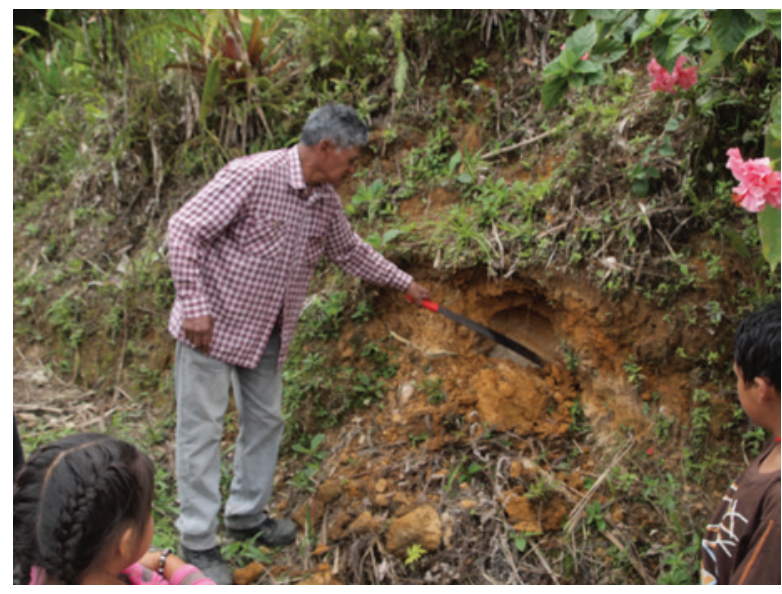

Figura 3. Alipio Mora, Comunero.

En cada una de las comunidades se procesó la arcilla, una vez recolectada se la secó, la trituramos, la tamizamos, para sacar las impurezas, le agregamos agua y la amasamos hasta conseguir una masa uniforme. Al mismo tiempo se elaboraban esteques con caña guadua de la zona, implementando técnicas de desbastamiento de la madera. Estos procesos se desarrollaron siempre acompañados de la narración de sus memorias, de sus vivencias y problemas cotidianos.

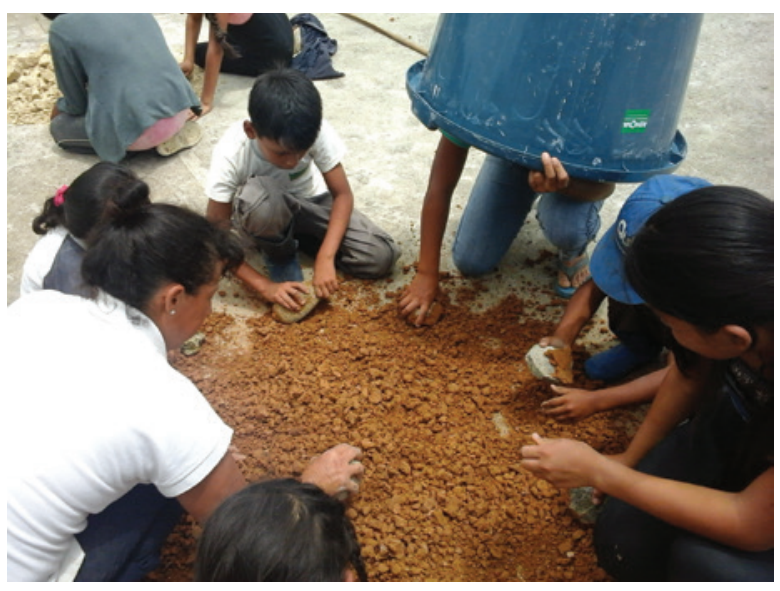

Figura 4. Procesando el barro.

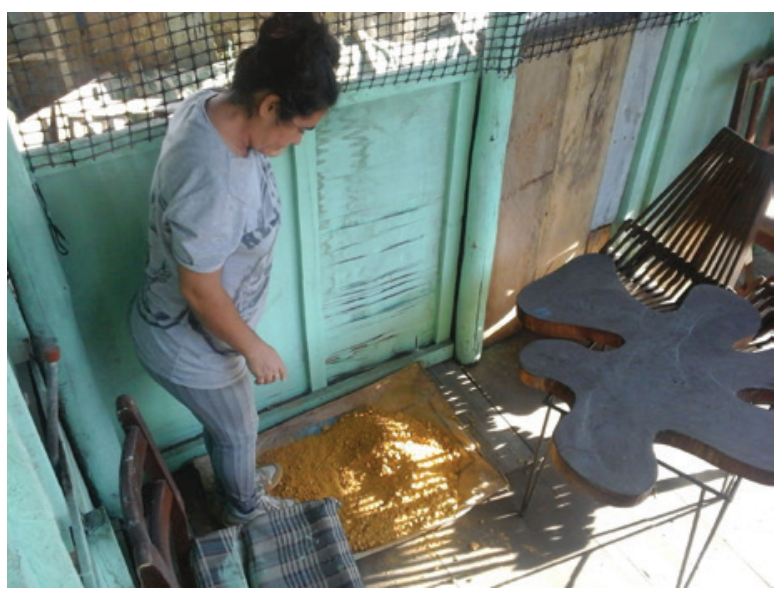

Figura 5.Anope, Procesando el barro. Pacto

Una vez amasado el barro se hace un llamado a sentir y topar el material, presionando el barro entre los dedos para percibir la forma, la textura y la huella que deja la mano. La intensión del ejercicio es que los participantes sientan sus cualidades, su temperatura, su suavidad, su ductilidad, su humedad, etcétera y perciban la infinidad de formas que se producen. Luego, con los ojos cerrados, se forma una esfera entre las manos para incidir en ella con la presión de los dedos y sentir el espesor que debe tener una pieza cerámica. Aprendieron como se construye vasijas con la técnica de cordel porque permite crecer sin necesidad de estructura; este ejercicio habilita a los talleristas a adquirir destrezas.

Por medio de la ductilidad de la arcilla se construyeron vasijas y en ellas se imprimieron las huellas que son las que nos permiten interpretar su entorno y darle una característica propia al objeto. Se impartió conocimientos de diseño para la decoración de las cerámicas en base a la técnica de incisión y a la pintura con óxidos, el engobe. Se decoraron las piezas construidas con 
los motivos que los talleristas seleccionaron de la introspección en su mundo.

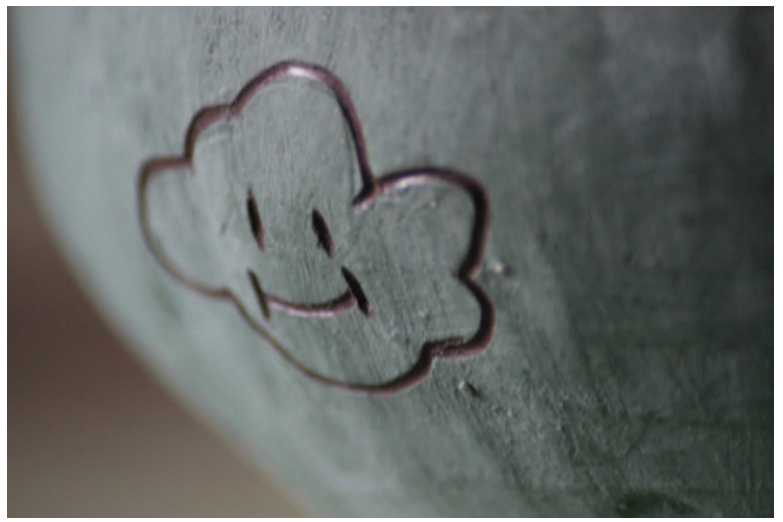

Figura 6. Técnica de incisión sobre engobe.

\section{Experiencias}

En Tulipe los talleres se desarrollaron en las instalaciones de la escuela Alfonso Moreno Bellido -atravesando una serie de requisitos burocráticos para acceder a sus espacios-, porque los talleristas no quisieron hacerlo en el "Museo de Sitio de Tulipe" -como habíamos pensado los investigadores idealizando el espacio ${ }^{7}-$ y no había un espacio comunitario porque el museo había ocupado el que estaba previsto para su construcción.

Don Giovanni Valencia (43 años), dueño de un pequeño hotel en Tulipe nos narró:

El pueblo tenía la cancha donde ahora está el museo... todos en un inicio estábamos ilusionados, creímos que todo iba a ir mejor... pero con el tiempo nos dimos cuenta... todavía no nos reconocen lo que cedimos el terreno... (Valencia, 2014)

Los talleres en Tulipe se proyectaron como un acontecimiento familiar, participaron abuelas, padres y madres, hijos y nietos, se estableció un diálogo con ellos y entre ellos, doña

6 Para ese entonces, el Museo de Sitio de Tulipe y su administración enfrentaba sus propios problemas de autoridad. En estos dos últimos años han cambiado sus autoridades en cuatro ocasiones, dejando acéfala la coordinación y cada vez se agudiza más la incomunicación con la comunidad.

7 Los investigadores entramos en la comunidad creyendo que la relación entre el museo y la comunidad era idílica. (JÄGER, 2003)
Rosa Elvira Córdova (72 años), colombiana de nacimiento y ceramista por tradición, nos contó como aprendió la cerámica y nos mostró cómo ella construye las piezas:

Mi abuela hacía cerámica y yo le veía, ella no quería que nadie le vea, pero yo me escondía, así aprendí. Mi abuela hacía trabajos en arcilla, buena masa. Se seca la arcilla, se muele, se cierne y se va amasando bonitamente. Ella salía a vender los barros, tiñéndoles de color negro. Ella hacía unos pondos grandes y les quemaba con leña, haciendo un hueco grande. Para quemar alistaba bastante leńa seca y le seguía poniendo leña, leña, leña. La quema estaba cuando los tiestos sonaban como una campana, ahí estaban quemados. (Cordova, 2014)

Se realizaron recorridos para reconocer sus alrededores y hacer un compendio de la flora y la fauna, relatándonos algunas memorias y algunas convivencias comunitarias. Se decoraron las piezas con los motivos que los talleristas seleccionaron de la reflexión de su mundo.

El taller en Tulipe se caracterizó por la confianza y camaradería, se construyeron piezas de mayor tamaño y con mayor destreza, es notorio como el aprendizaje se asimiló a su hacer.

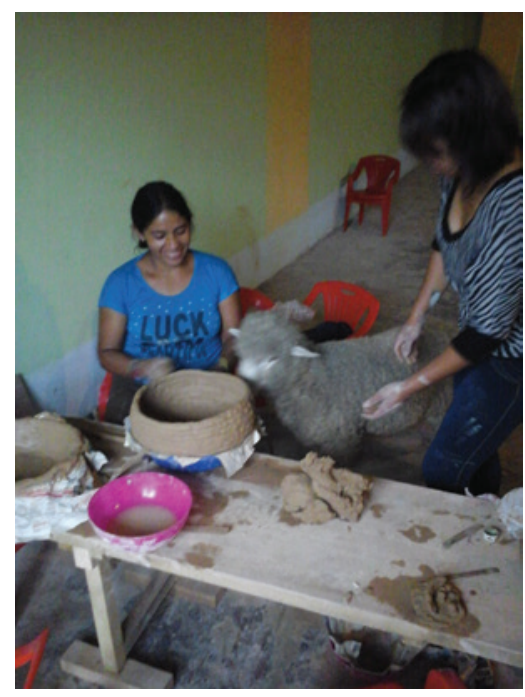

Figura 7. Clemencia Simbańa y Mariana Villareal. Tulipe.

En Anope, los habitantes de la comunidad nos guiaron por el pueblo, mostrándonos las construcciones, la topografía y con ello los 
emplazamientos y señalizaciones antiguas y modernas, narrándonos sus memorias e historias vividas o transmitidas por la tradición oral o sus propias interpretaciones de la historia, empoderándose siempre del espacio habitado.

En Anope, la Casa Comunal del pueblo estuvo a disposición de los pobladores sin conflictos de autoridad.

En una ocasión, por pedido de sus pobladores, se leyó capítulos del texto de Frank Salomon, (1997) Los yumbos, Niguas y "Colorados". Durante la Colonia Española: Etnohistoria del Noroccidente de Pichincha, Ecuador:

Un fuerte contingente de los yumbos habitó la banda sur del Río Guayllabamba al este de su unión con el río Alambi, (los) pueblos, situados por la mayor parte cerca de los ríos tributarios al Alambi incluyeron (...) a dos comunidades posiblemente formadas durante la colonia, Guacpi y Anope. En el presente ensayo estas comunidades colectivamente reciben el nombre de yumbos septentrionales (SALOMON, 1997).

La lectura del texto abrió espacios para que los pobladores narren sus memorias y experiencias. Don Alipio Mora (2015) relató una historia en relación con los emplazamientos construidos en el lugar. La tola con la construcción de la iglesia en su cima y cercenada para cederle el espacio a la cancha de volei:

Es una historia de los que habían estado cavando aquí en $\mathrm{mi}$ terreno, que había sido del señor César Tixilema. Se habían puesto a cavar la tola (para encontrar un entierro)... ya ellos le sintieron cerca porque disque sonaba como cajón hueco ahí dentro, y disque llega una hija a darles el almuerzo y ellos disque han prendido las barras en el suelo, las cuatro barras a los costados del hoyo y (...) disque escucharon cómo una dinamita. $\mathrm{Al}$ acercarse (...) se largaron las barras, estando bien prendidas, se largaron las cuatro barras adentro y un olor a azufre salió, y ya disque no encontraron las barras, ni el cajón... Y siempre molesta verá. Los ruidos son espíritus que llegan. (MORA, 2015)

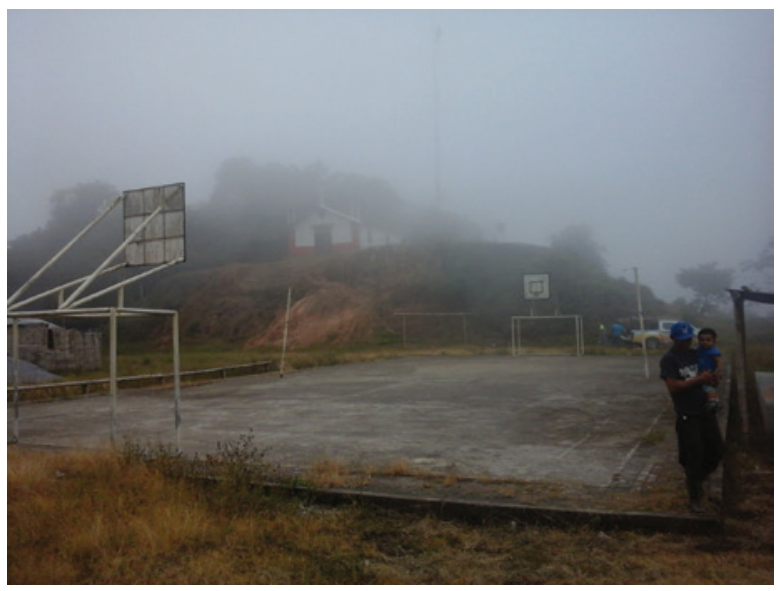

Figura 8. Iglesia de Anope y cancha de volei.

En el trajín cotidiano el colono se confrontan con objetos que han escapado del dispositivo museal, por lo tanto que han perdido el sentido que tenían, dejando que los colonos les den una significancia que les interpela.

En Pacto, las participantes tenían vínculos de parentesco, por lo que se puso a disposición del taller una estancia en la casa del padre de la Sra. Yolanda Velazco organizadora del taller.

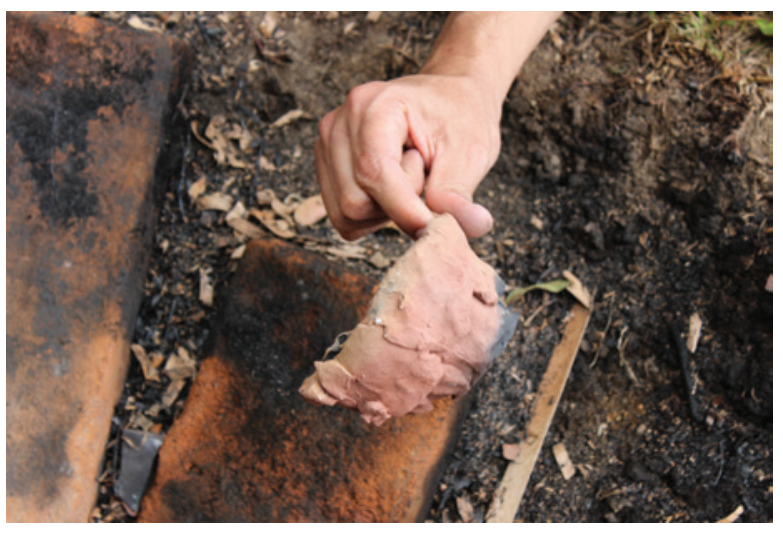

Figura 9. Quema al aire libre. 
Se construyó en cada una de las comunidades un horno de oxidación al aire libre, se quemó las piezas, recolectando leña al borde de las carreteras o con viruta donada por las carpinterías. Se apilan las piezas y se acumula la leña. Este acto se produce como una especie de ritual o fiesta.

En Pacto y Anope se realizaron los talleres a cambio de la extracción de arcilla, el contacto fue directo con los interesados y con finalidades claras. La comunidad de Tulipe estaría en condiciones de enfrentar su propia producción y las comunidades de Pacto y Anope tendrían que consolidar las técnicas aprendidas.

\section{Objeto cerámico y exposición}

La vasija cerámica, como un objeto al final del camino, como el producto donde se han puesto todos los esfuerzos y en donde confluyen todos los "fragmentos discursivos" abiertos en la investigación, es un objeto silente que exterioriza y a la vez concluye los procesos vividos para constituirse como lo que es (Jäger, 2003).

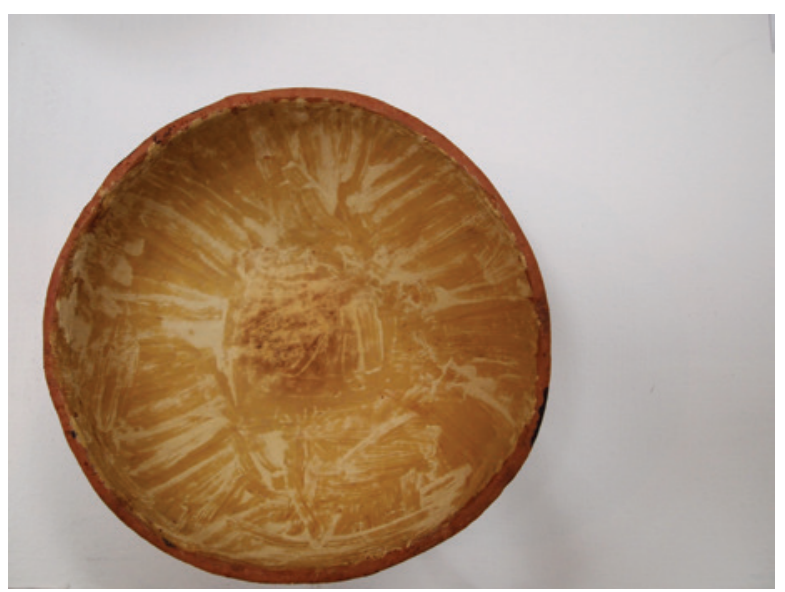

Figura 10. Objeto cerámico

La capacidad lúdica y sensible de las artes para adaptarse a las herramientas, a las técnicas y a los materiales, en el trazo de formas y en la factura de los objetos que pueblan el espacio y que constituyen la realidad, durante la interacción entre los sujetos en un espacio y un momento específico, como actos insertos en la vida. Estos actos u objetos se convierten en estructuras de significado que se incorporan a un universo epistémico para contribuir a su propio conocimiento, operando como facilitadores o desestabilizadores del sentido. El objeto se presenta como un nuevo elemento de lenguaje que pasa a constituir un suceso epistémico que entra a circular en los dispositivos discursivos como un acontecimiento que marca la diferencia entre un antes y un ahora. Intentamos impulsar el reconocimiento de sus propias visualidades, a partir de sus experiencias en la percepción del espacio que les rodea para inscribir al acto creativo en su mundo de representaciones. (Bishop; Groys, 2009),

Desde la modernidad, el arte ha pretendido escapar de los dispositivos discursivos, manteniéndose en posiciones críticas frente al discurso hegemónico, ha construido objetos que circulan, abriendo signos que implementan nuevas formas de ver y de comprender el mundo.

La exposición es el momento de culminación de una producción artística entre las relaciones: materia, forma y contenido y la intensión del artífice, por medio de la factura. En la exposición el objeto comienza a circular con sus propios signos que serán interpretados por los espectadores o por los usos que se les otorga, donde su pertinencia sea tangible y haga sentido.

La exposición, "Cerámicas Tulipe" (diciembre 2014), se produjo como una consecuencia de los procesos vividos en los talleres, como un evento que cierra las diferentes metodologías y eventos implementados en la investigación. La exposición es donde se visualiza el resultado de los aprendizajes tanto de los colonos como de los investigadores.

Las piezas de los pobladores de noroccidente de Pichincha fueron expuestas en diálogo con las piezas que alberga el Museo Arqueológico Rumipamba, lugar antiguamente ocupado por culturas quiteńas, desde el Formativo tardío (1500 a.C.), Desarrollo Regional (500 a.C. al 500 d.C.) y de Integración (500 d.C. al 1500 d.C.), en el noroccidente de la ciudad de Quito. La exposición produce una ambiguación del espacio y le da una continuidad histórica a los objetos. 

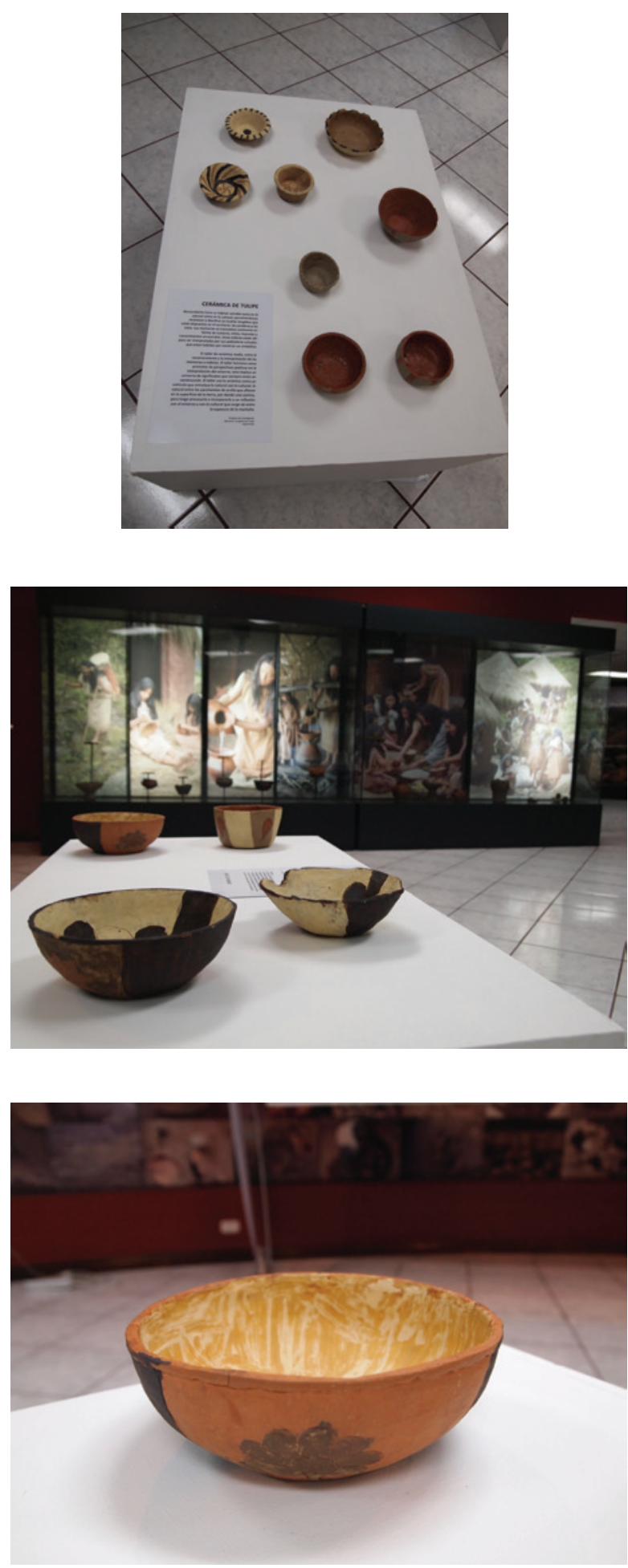

Figura 11,Figura 12 ,Figura 13.Exposición en el Museo Arqueológico Rumipamba.

La exposición en noroccidente se realizó en el Museo de Sitio de Tulipe. La escuela, Alfonso Moreno Bellido, asistió como parte integrante del proyecto educativo ya que los talleres de cerámica se desarrollaron en sus aulas. Se convocó a los estudiantes a visitar la exposición. Algunos niños eran parte del proceso del taller que ahora terminaba con la exposición. Al exponer el objeto, el signo recircula y se produce la apropiación por parte del público. En la exposición se actualiza el dispositivo educacional del museo ${ }^{8}$.

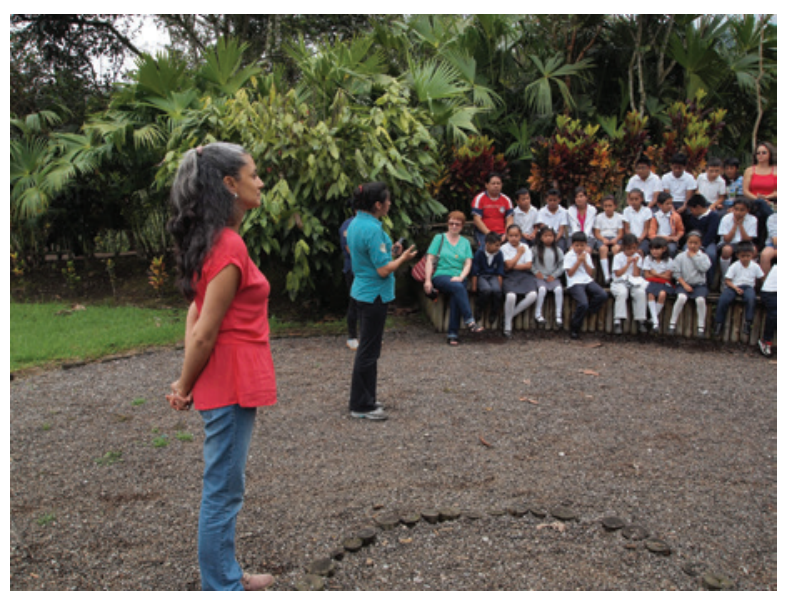

Figura 14. Inauguración de la exposición Museo de Sitio de Tulipe

Inauguración de la exposición Museo de Sitio de Tulipe con, Bernarda Icaza, Coordinadora de los Sitios Arqueológicos de Quito (2014-2016) y con la facilitadora del museo Flor Angélica Sánchez, habitante de Tulipe.

En la exposición se pone a circular los signos de los objetos, producto del trabajo de los talleristas que transformaron el material encontrado en la zona, abriendo la posibilidades a los pobladores de que puedan producir con un lenguaje inserto en los circuitos actuales de las visualidades, a partir de un conocimiento relacionado con el arte y de técnicas cerámicas aprendidas, desde un lugar de enunciación, en este caso el del colono de noroccidente de Pichincha atravesado por algunas circunstancias.

El siguiente paso sería implementar la autonomía de la producción y distribución.

\section{Conclusiones: intercambio y conocimiento}

El Taller fue el espacio donde convergieron todas las actividades de la investigación:

8 Tomando en cuenta que esa es la función del "museo de sitio" que debe devolver a la comunidad. (CRESPO, L., 2017) 
Hemos podido constatar que el arte está estrechamente vinculado a la ciencia porque es una experiencia que busca respuestas concretas, que desarrolla tecnologías y experimenta con materiales.

Se ha reconocido el territorio, se ha mapeado y socializado con los colonos la ubicación de las afloraciones de arcilla.

En el taller, los colonos han aprendido las destrezas de la técnica cerámica, la preparación de pastas y la construcción de un horno al aire libre. Han enfrentado procesos de interpretación, traduciendo, significando y por tanto simbolizando las memorias, la vivencias, los rumores, las leyendas, etcétera, con lo que van originando signos de pertenencia con su entorno natural y con el entorno construido.

Los colonos vienen de realidades diversas, abiertos a percibir nuevas estructuras interpretativas para movilizar los diferentes dispositivos discursivos, a través de procesos de identificación y desidentificación. (Jäger, 2003).

Dialogando con Suely Rolnik en el texto: "El Arte cura", la posibilidad de acercarse al barro como elemento curativo, a la cerámica como proceso de producción de objetos utilitarios y a ambos como fuente de conocimientos ancestrales, nos llevó a confrontarnos con la vida, partiendo de la manipulación del barro, a través de una experiencia estética tan esencial como la que tuvo el primer ser humano, donde se abre el mundo para ser interpretado, a partir de lo fenoménico (Rolnik, 2001). Ya sea, por el nivel de "educación" o porque su mundo -el de un campesino- está en lo sensible y en el conocimiento empírico de su entorno, sin estar atravesados por la homogenización del discurso (Bishop, C., Groys, B. 2009).

Para los investigadores la ejecución del taller ha funcionado como un acto creativo de aprendizaje y de interpretación, como facilitadores, y además como una devolución fenómenica a sus propios afectos y realidades construidas.

El Museo de Sitio de Tulipe intenta rescatar la utilidad ritual del monumento, pero se queda en un pastiche y en una folklorización de los signos, sin que los habitantes participen ni en el guión museográfico ni en la organización de sus eventos (Crespo, L., 2017). "Si el discurso cambia, el objeto no sólo cambia su significado, sino que se convierte en un objeto diferente, pierde su identidad previa" (Jäger, 2003. P. 76). Los signos actuales son impuestos por una "metacultura" o el culto a lo cultural

En este lapso, el proyecto METATU, vio la incapacidad de la institución "cultura" del Estado-Nación para mediar entre las culturas vivas y la trasferencia de las culturas desaparecidas. El museo ha recuperado para si el uso romántico de la ritualidad y hace una apología del uso astronómico, siendo completamente ajenos a los intereses de los pobladores. Los objetos pierden sentido o adquieren sentido para uno u otro dispositivo del discurso o de los discursos en conflicto.

Esta investigación ha pretendido exponer varios puntos de vista, tomando en cuenta los enunciados del campo académico que se han formulado previamente. Se hizo una evaluación empírica sobre el campo fenoménico del sector con el componente exhortativo de las artes, permitiendo unos resultados abiertos como lo exige el análisis del discurso. (Meyer, 2003)

\section{Bibliografía}

Bishop, C. \& Groys, B. (2009) Tate Modern, issue 16: Sumer 2009. London, England. www. tate.org.uk/context-comment/articles/ bring-noise, 10-05-2017

Bourdieu, P. (2001). Poder, derecho y clases sociales. Bilbao, España. Henao.

Cartagena, M. F. \& León, C. (2014). El museo desbordado: Debates contemporáneos en torno a la musealidad (pag. 78). Quito, Ecuador: ABYA YALA.

Cámara, M. (2014). Ensayo de un crimen, Sobre un happening de Oscar Masotta y una instalación de Oscar Bony. En Imágenes y realismos en América Latina. (pag. 7-8-12). Buenos Aires, Argentina: ALMERANA

Crespo, C. (2016). Entre lo Tangible e Intangible en Noroccidente de Pichincha. Manuscrito presentado para publicación.

Crespo, L. (2017), El museo de sitio de Tulipe, en el proceso de construcción identitaria y narrativa 
visual de la actual población de Tulipe, Tesis de maestria no publicada, Universidad Andina Simón Bolívar, Quito-Ecuador.

Fajardo, R. (2008). La investigación en el campo de las Artes Visuales y el ámbito académico universitario (Hacia una perspectiva semiótica). Revista de Ciencia sociales y Humanísticas , 10 (2), P. 85-86-87-98.

Gadamer, H. G. (1993). Fundamentos de una Hermenéutica. Verdad y Método. Filosófica. Salamanca, España: Ediciones Sígueme.

Guber, R. (2001). La etnografía, método, campo y reflexividad. Bogotá, Colombia: Grupo Editorial, Norma.

Jäger, S. (2003). "Discurso y conocimiento: aspectos teóricos y metodológicos de la crítica del discurso y del análisis de dispositivos", en: Métodos de análisis crítico del Discurso, Comp. Ruth Wodak, Michael Meyer. Barcelona, España: Editorial Gedisa, S.A.

Jara, H. (2006). Tulilpe y la cultura Yumbo: Arqueología comprensiva del subtrópico quiteño (Vol. 1 y 2). Quito, Ecuador: FONSAL, TRAMA. P.

Kirshenblatt-Gimblett, B. (2004). "Intangible heritage as metacultural production." (Vol. 56). Museum International.

Krauss, R. (1979). "La escultura en el campo expandido". Octover (8). P. 30-44.

Latour, B. (2007). Nunca fuimos modernos. Ensayo de antropología simétrica. Buenos Aires, Argentina: Siglo XXI Editores S.A.

Lacan, J. (1964). El seminario de Jacques Lacan. Los cuatro conceptos fundamentales del Psicoanálisis. "La Anamorfosis", Buenos Aires, Argentina: Paidos.

Meyer, M. (2003). Entre la teoría, el método y la política: la ubicación de los enfoques relacionados con el ADD (Análisis Critico del Discurso), en: Métodos de análisis crítico del Discurso, Comp. Ruth Wodak, Michael Meyer. Barcelona, España: Editorial Gedisa, S.A.

Nora, Pierre. (2008). Entre la memoria y la historia: Problemática de los lugares. Montevideo, Uruguay: Gallimar, Trilce. P. 22-23.

Rhoades, R. (2001). Tendiendo puentes entre los paisajes humanos y naturales: La investigación participativa y el desarrollo ecológico en una frontera agrícola andina. Quito, Pichincha, Ecuador: ABYA YALA.

Rolnik, S. (2001). ¿¿El arte cura? Barcelona, España: MACBA Museo d"Arte Contemporáneo de Barcelona.

Salomon, F. (1980). Los Señores Étnicos de Quito en la Época de los Incas. Otavalo, Ecuador: Colección Pendoneros, Instituto Otavaleño de Antropología.

Salomon, F. (1997). Los Yumbos, Niguas y Tsachila o "Colorados" durante la colonia española: Etnohistoria del noroccidente de Pichincha. Quito, Pichincha, Ecuador: ABYA YALA. P. 31

Scollon, R. (2003). "Acción y texto: para una comprensión conjunta del lugar del texto en la (inter)acción social, el análisis mediato del discurso y el problema de la acción social", en: Métodos de análisis crítico del Discurso, Comp. Ruth Wodak, Michael Meyer. Barcelona, España: Editorial Gedisa, S.A.

Valarezo, G. (2001). "La tierra y la sociedad de Nanegal desde los tiempos aborígenes". En RHOADES, Tendiendo puentes entre los paisajes humanos y naturales: la investigación participativa y el desarrollo ecológico en una frontera agrícola andina (págs. 36-38-40-41). Quito, Ecuador: ABYA AYALA.

Yasunidos, (2015, 14 de abril) "Pacto dice no a la minería". Extraído el 15 de junio de 2016 desde: sitio.yasunidos.org/es/comunicacion/ blog/184-pacto-dice-no-a-la-mineria.html

\section{Entrevistas}

Cordova, M. (14 de Abril de 2014). Memorias Tangibles de Tulipe. (C. CRESPO, Entrevistador) Tulipe.

Cordova, R.E. (17 de mayo de 2014). Memorias Tangibles de Tulipe. (C. CRESPO, Entrevistador) Tulipe.

Flor, A. (5 de mayo de 2015). Memorias Tangibles de Tulipe. (L. A. CRESPO, Entrevistador) Anope.

Guillen, I. (16 de Mayo de 2015). Memorias Tangibles de Tulipe. (C. CRESPO, Entrevistador) Sanhuangal.

Merino, C. (16 Junio 2015). Memorias Tangibles de Tulipe. (C. CRESPO, Entrevistador) Tulipe. 
Miño, L. (14 de Marzo 2014). Memorias Tangibles de Tulipe. (C. CRESPO, Entrevistador) Tulipe.

Mora, A. (17 de febrero 2015). Memorias Tangibles de Tulipe. (C. CRESPO, Entrevistador) Anope.

Valencia, J. (10 de Junio 2014). Memorias Tangibles de Tulipe. (C. CRESPO, Entrevistador) Tulipe.

\section{Fotografías}

Crespo, C. (2015). Tola e iglesia en Sanhuangal (Fotografía) Fig. 1

Crespo, C. (2015). Caminata en Anope (Fotografía) Fig. 2

Crespo, C. (2015). Alipio Mora. Comunero (Fotografía) Fig. 3

Crespo, C. (2015). Procesando el barro. Anope (Fotografía) Fig. 4

Crespo, C. (2015). Procesando el barro. Pacto (Fotografía) Fig. 5

Albán, P. (2015). Técnica de incisión sobre engobe. Anope (Fotografía) Fig. 6

Crespo, C. (2015). Clemencia Simbaña y Mariana Villareal. Tulipe (Fotografía) Fig. 7

Crespo, C. (2015). Iglesia de Anope en la tola cortada. Tulipe (Fotografía) Fig. 8

Albán, P. (2015). Quema al aire libre. Tulipe (Fotografía) Fig. 9

Crespo, C. (2014). Objeto Cerámico. Quito (Fotografía) Fig. 10

Crespo, C. (2015). Exposición Museo "Parque Rumipamba". Quito (Fotografía) Fig. 11

Crespo, C. (2015). Exposición Museo "Parque Rumipamba". Quito (Fotografía) Fig. 12

Crespo, C. (2015). Exposición Museo "Parque Rumipamba". Quito (Fotografía) Fig. 13

Crespo, C. (2015). Exposición Museo "Parque Rumipamba". Quito (Fotografía) Fig. 14

Crespo, C. (2015). Inauguración. Exposición Museo de Sitio de Tulipe. Tulipe (Fotografía) Fig. 15 